\title{
Risk factors for symptomatic venous thromboembolism following surgery for closed ankle fractures: a case-control study
}

Knut Stavem, MD, MPH, MBA, $\mathrm{PhD}^{1,2,3}$

Stein Arve Skjaker, MD ${ }^{4}$

Henrik Hoel, MD 5

Markus Georg Naumann, MD ${ }^{6}$

Ulf Sigurdsen, $\mathrm{MD}, \mathrm{PhD}^{7}$

Waleed Ghanima. MD, $\mathrm{PhD}^{1,8}$

Stein Erik Utvåg, $\mathrm{MD}, \mathrm{PhD}^{1,7}$

${ }^{1}$ Institute of Clinical Medicine, University of Oslo, Norway

${ }^{2}$ Health Services Research Unit, Akershus University Hospital, Norway

${ }^{3}$ Department of Pulmonary Medicine, Medical Division, Akershus University Hospital, Norway

${ }^{4}$ Section for Orthopaedic Emergency, Orthopaedic Department, Oslo University Hospital, Norway

${ }^{5}$ Department of Vascular Surgery, Oslo University Hospital, Aker, Norway

${ }^{6}$ Department of Orthopaedics, Østfold Hospital, Norway

${ }^{7}$ Department of Orthopaedics, Akershus University Hospital, Norway

${ }^{8}$ Department of Medicine, Østfold Hospital, Norway

Corresponding author: Knut Stavem, Health Services Research Unit, Akershus University Hospital, Lørenskog, Norway

Email: knut.stavem@medisin.uio.no 


\section{ABSTRACT}

Background: We analyzed risk factors for venous thromboembolism (VTE) within 6 months after surgery for closed ankle fractures

Methods: This was a case-control study based on data from chart review in a cohort of patients having open reduction and internal fixation (ORIF) for closed ankle fractures in two large general hospitals 2009-2011. Cases with symptomatic VTE (pulmonary embolism or deep venous thrombosis) were identified in the cohort, and additional cases of VTE were identified by computerized search of discharge diagnoses in the same hospitals in 20042008 and 2012-2016. In total, we identified 60 cases with VTE and compared with 240 randomly selected controls among 998 patients without VTE in the cohort. Risk factors were assessed using logistic regression analysis.

Results: Among cases, 27 (45\%) had pulmonary embolism, 33 (55\%) deep venous thrombosis. Those with VTE were older, had higher BMI, had more often a family history of VTE, and more often had antibiotic prophylaxis during surgery than controls. In multivariable logistic regression analysis age/10 (OR $25.75,95 \% \mathrm{Cl} 3,52$ to $188.44, p=0.001)$, $(\mathrm{age} / 10)^{2}(\mathrm{OR} 0.77,95 \% \mathrm{Cl} 0.65$ to 0.93, $p=0.005)$, BMl (1.15 per $\mathrm{kg} / \mathrm{m}^{2}, 95 \% \mathrm{Cl} 1.07$ to $\left.1.24, p<0.001\right)$ and Charlson comorbidity index $\geq 2$ vs. 0 (OR $0.27,95 \% \mathrm{Cl} 0.08$ to $0.92, p=0.036$ ) and 1 vs. 0 (OR $0.27,95 \% \mathrm{Cl} 0.09$ to $0.86, p=0.026$ ) were associated with VTE within 6 months of surgery.

Conclusions: The odds of symptomatic VTE within 6 months of ORIF increased with increasing age and BMI, but were lower with increasing comorbidity.

Keywords: Ankle fracture; ORIF; venous thromboembolism; deep venous thrombosis; lung embolism; case-control; risk factors 


\section{Introduction}

Venous thromboembolism (VTE), which includes deep vein thrombosis (DVT) and pulmonary embolism (PE), is a well-known complication to orthopedic surgery or injury to the lower limb. The incidence rate of symptomatic VTE following ankle surgery is 0.3 to $3.5 \%$ [1-7]. The incidence rate of VTE, however, varies by procedure [4].

The American College of Chest Physicians (ACCP) recommends against pharmacological thromboprophylaxis in isolated lower leg injuries requiring leg immobilization [8]. Other reports support this, but underscore that patient-specific risk factors for VTE should be used to assess patients individually $[1,9,10]$.

A recent review and a meta-analysis $[1,11]$ reported that age $[5,12-$ $16]$, injury severity $[15,16]$, obesity $[14,16,17]$, immobilization $[5,13,15]$ and tourniquet time $[5,18]$ were risk factors for VTE following foot and ankle injury or treatment in several studies. There are very limited reports on the risk factors for VTE after surgery for isolated ankle fractures, despite these fractures being common [19]. Previous studies have identified age [6, 20], body mass index (BMI) [21], comorbidity [6, 20], heart disease [21], noninsulin-dependent diabetes mellitus (NIDDM) [20], COPD [20] and dependent functional status [21] as risk factors for VTE following surgery for ankle fractures. Because of the low incidence of VTE episodes and small sample sizes; however, most studies had limited power to conduct multivariable analysis.

We have previously reported a 3-month incidence of symptomatic VTE following open reduction and internal fixation (ORIF) for closed ankle fractures 
of $1.4 \%(14 / 1011)$ in a cohort between 2009 and 2011[22], but the number of cases of VTE was considered too small to perform a meaningful analysis of risk factors. To analyze risk factors, we extended the study by including more patients with VTE (2005-2008 and 2012-2016) for a case-control analysis. Therefore, this study aimed to determine risk factors for symptomatic VTE within 6 months after ORIF for closed ankle fractures using a case-control design.

\section{Patients and methods}

\subsection{Study design and population}

This was a case-control study, comparing cases of symptomatic VTE with controls without VTE. The study was an extension of a historical cohort study, which included all patients $\geq 18$ years of age, who were treated for closed ankle fractures with ORIF between January 1, 2009 and December 31, 2011 at two Norwegian hospitals, Østfold Hospital and Akershus University Hospital $[22,23]$

We identified patients through discharge diagnoses from the hospital information systems (10th revision of the International Classification of Diseases codes S82.3-S82.9, S93.2 and S93.4) [24] combined with surgical procedure codes (Nordic Medico-Statistical Committee Classification of Surgical Procedures: codes NHJ00-NHJ98 and NHE 99) [25]. In total, 1,149 patients were eligible for chart review. We excluded 138 patients for the following reasons: came from outside the hospitals' catchment areas, had misclassified fractures types or year of fracture, had suffered polytrauma or high energy trauma (motor vehicle or motorcycle accidents, bicycle accidents, skiing accidents, pedestrians being hit by any of the above, and falls from a height of $\geq 3 \mathrm{~m}$ ), that were conservatively treated, had cognitive problems or 
apoplexy and were unable to respond to questionnaires (Fig. 1). Hence 1,011 patients were eligible for the study.

The patients in both hospitals were treated according to the recommendations of the Swiss Arbeitsgemeinschaft für Osteosynthesefragen (AO) and the American Orthopedic Trauma Association (OTA) [26].

\subsection{Medical record review and variables}

All electronic medical records and radiological images in the 2009-2011 cohort were reviewed by an orthopedic surgeon (MGN or US) to verify the recorded diagnosis and procedures and to collect information on demographics including $\mathrm{BMI}$ in $\mathrm{kg} / \mathrm{m}^{2}$ at the time of surgery, physical status before surgery [American Society of Anesthesiologists (ASA) classes I-III: I, completely healthy fit; II, mild systemic disease; and III, severe systemic disease] [27], diabetes (yes or no), current smoking status (yes, no, or unknown), use of corticosteroids (yes or no), fracture classification (from radiographs: using the Weber classification and into uni-, bi- and trimalleolar fractures), treating hospital, whether surgery was performed within 8 hours of trauma, the insertion of one or more syndesmosis screws (yes or no), the duration of surgery (in minutes), length of stay (LOS) (in days), and the prophylactic use of anticoagulants [(low molecular weight heparin (LMWH) or warfarin)].

\subsection{Cases of venous thromboembolism}

In this cohort we identified 13 cases with verified VTE during the first 6 months following ORIF. To increase the number of cases, we searched for potential cases from the hospital information systems of the same two hospitals in 2005-2008 and 2012-2016, using the same criteria for discharge 
diagnosis as for the 2009-2011 cohort (see above) combined with an ICD-10 discharge diagnosis of (180.* | 182. ${ }^{*} \mid$ 126. $)$ within 6 months (183 days) of the day of surgery. The patients were followed for potential VTEs until June 30, 2017.

The electronic medical records were reviewed to verify that the cases fulfilled the study criteria (by HH or MGN), and to abstract supplementary information on the type of VTE, diagnostic procedures, previous VTE, cancer during the past 5 years, hormone replacement therapy (HRT), oral contraception, information on comorbidities to score Charlson comorbidity index (CCl) [28], and family history of thrombophilia (protein S deficiency, antithrombin III deficiency, activated protein $\mathrm{C}$ resistance), in addition to the variables registered for the 2009-2011 cohort, as described above. The charts for the VTE cases from 2009-2011 were re-reviewed to collect the same variables. In total, we identified 60 unique cases with VTE within 6 months following ORIF 2005-2016 (Fig. 1).

\subsection{Controls}

In the original 2009-2011 cohort all variables that were considered potential risk factors for VTE were not registered, but were collected for the present study. To reduce additional work with supplementary chart review without compromising study power, we decided to use four controls per case instead of using all patients in the cohort without VTE as controls, as there is usually little gain in precision by including more than four controls per case [29]. As we had altogether 60 cases, we randomly selected 240 controls from the 2009-2011 cohort without VTE ( $=998)$. These charts were reviewed again (by SAS, MGN, SEU or KS) registering supplementary variables as for the cases of VTE. 


\subsection{Statistical analysis}

We present the patients, their fractures and their surgery with the mean (range or SD), median (interquartile range) or number (\%) values and compared descriptive variables between cases and controls using the MannWhitney $U$ test, chi-square test or Fisher's exact test, as appropriate.

As cases were selected before, during the same time-period or after the controls, we compared descriptive statistics for the cases across three time periods (2004-2008, 2009-2011, 2012-2016) using the Kruskal-Wallis test, chi-square test or Fisher's exact test, as appropriate.

We used multivariable logistic regression analysis to determine risk factors for VTE, using VTE (yes or no) as the dependent variable, presenting results as odds ratios (OR). As we had only 60 cases of VTE for analysis, before the analysis we chose to include a maximum of eight variables in multivariable models.[30] As independent variables we chose to include age/10, sex, BMI, CCI $(0,1, \geq 2$ ), previous VTE (yes or no) and thrombosis prophylaxis (yes or no), based on the literature and availability of data.

We used Stata (version 15.1, Stata Corporation, College Station, TX, USA) for all statistical analyses, with a significance level of $p<0.05$ in twosided tests. Model fit was assessed using Akaike information criterion [31].

The Regional Committees for Medical and Health Research Ethics, Health Region South East (approval no. 2012/384) and the Ombudsman for research at Akershus University Hospital approved the study.

\section{Results}

Among patients with verified VTE following surgery, 27 (45\%) had PE, 33 (55\%) had DVT in the operated leg (15 above the knee, 18 below the knee). Patients with VTE were older, had higher BMI, had more often a family history 
of VTE, and more often had antibiotic prophylaxis during surgery than controls (Table 1). All PEs were verified by CT angiography. Of the DVTs, 30 (91\%) were verified by doppler-ultrasonography, 1 by venography, 1 by CT angiography, and 1 by doppler-ultrasonography and venography.

The cases of VTE showed little difference in descriptive statistics across the three time periods; there was only a difference in postoperative LOS and antibiotic prophylaxis, with a lower LOS and higher proportion having antibiotic prophylaxis during the latest (2012-2016) time period (Table 2). In total, 21 (35\%) of the 60 VTE events occurred within 30 days of surgery and 53 (88\%) within 90 days.

In multivariable logistic regression analysis age/10 (OR 25.75, 95\%Cl $3,52$ to $188.44, P=.001)$, (age/10) $)^{2}$ (OR $0.77,95 \% \mathrm{Cl} 0.65$ to $0.93, P=.005$ ), BMI per $\mathrm{kg} / \mathrm{m}^{2}$ (OR $1.15,95 \% \mathrm{Cl} 1.07$ to $\left.1.24, P<.001\right)$ and $\mathrm{CCl} \geq 2$ vs.0 (OR $0.27,95 \% \mathrm{Cl} 0.08$ to $0.92, P=.036$ ) and 1 vs. 0 (OR $0.27,95 \% \mathrm{Cl} 0.09$ to 0.86 , $P=.026$ ) were associated with VTE within 6 months of surgery (Table 3). Because of non-linearity of age as a predictor, we included age squared in the model, which contributed to a better model fit.

\section{Discussion}

The major findings of this study were that in multivariable analysis increasing age and increasing BMI were associated with symptomatic VTE within 6 months of ORIF for ankle fracture. In addition, $\mathrm{CCI}$ was associated with VTE; however, this was in an unexpected direction, as those with comorbidities had lower odds of VTE than those without.

The finding of an association between age and VTE confirms previous reports in foot and ankle surgery [4, 6, 20, 32]. In contrast, one study did not find an association between age and post-operative VTE [2]. 
The association between BMI and postoperative VTE also is in line with previous findings for BMl or obesity in foot and ankle surgery $[2,4,6,20,21$, 32]. This finding is, however, not universal across all studies [7].

The finding of lower odds of VTE for those with comorbidities than for those without was unexpected, and we are uncertain about how to interpret this. This group had slightly longer duration of prophylaxis with LMWH than those without comorbidities, but there was no statistically significant multiplicative interaction between comorbidity and prophylaxis, or between comorbidity and age in the logistic regression models. However, it is notable that 45 out of 60 patients with VTE following ORIF had no previous comorbidity. It is possible that patients with comorbidity were monitored more closely, had better compliance with directions, were encouraged to earlier mobilization, or used more acetylsalicylic acid or other drugs that may confound the association between comorbidity and VTE, though we have no data on this.

These findings contrast findings in some previous studies that reported increased odds of postoperative VTE with comorbidity with CCI score >2 [20] or specific comorbidities such as NIDDM [12], heart disease [21] in ankle fracture surgery, or rheumatoid arthritis [33] or no increased odds of comorbidity for VTE following foot and ankle surgery [2].

We could not show a clear benefit of chemoprophylaxis on VTEs with OR $0.45(95 \% \mathrm{Cl} 0.12$ to 1.84$)$. However, this was not the focus of the study. A recent meta-analysis also reported no significant difference in the rates of VTE with or without chemoprophylaxis, independent of the criteria used for the detection of events [1]. Moreover, we could not confirm an association between a previous VTE and VTE following ankle fracture surgery as previously shown for foot and ankle surgery [32]. The OR of previous VTE for 
a new incident; however, was $2.89(95 \% \mathrm{Cl} 0.58$ to 14.42$)$ compared to those with no history of VTE. This lack of statistical significance may be related to the lack of statistical power in the present study.

The findings in different studies may not be comparable because of differences in study design, inclusion criteria, surgeries, follow-up periods, use of prophylactic treatment, methods to identify or detect case of VTE, or methods for analysis. For example, some previous studies were registerbased cohort studies [4, 21], and some were retrospective cohort studies [7] in contrast to the present hybrid of a retrospective cohort and case-control study. In addition, the studies accrued patients during different periods between 1995 and 2016, and there might have been some changes in practice throughout this period, compared to 2004-2016 as used in the present case-control study. Some studies also comprised patients from the same database $[4,21]$. Because of the limited number of cases, most studies did not conduct multivariable analysis.

Some challenges and limitations in the present study should be noted. We included patients with a symptomatic VTE up to 6 months after surgery, while some previous studies used 30 days [4, 21], or 90 days [2, 6, 20, 22]. In the present study only seven events occurred between 90 and 183 days after surgery. Therefore, this difference would have had little impact on the results.

In spite of accruing cases from a large population over 14 years, the number of VTE cases was limited, because of the low incidence of VTE after ankle fracture. This limited the statistical power of the study and the number of variables to be included in the multivariable analysis. In an ad-hoc power analysis, the study would be able detect an OR of 2.3 to 2.9 for a risk factor for VTE between cases and controls, given a power 0.80 , a $5 \%$ significance level and a proportion of 0.4 to 0.1 of the risk factor in the control group. 
Increasing the number of controls to the double $(n=480)$ would only marginally influence the ORs that could be detected (2.2 to 2.7).

We used the same criteria for the identification of cases and controls, and the procedures used for the collection of exposure data from the electronic medical records were the same for cases and controls, thus reducing the possibility of differential misclassification. However, about $75 \%$ of the cases were from within 5 years before or 5 years after the period for selection of controls. During the period of the study, the use of antibiotic prophylaxis and the LOS decreased; otherwise, the descriptive statistics were similar across the three periods.

Case-control studies are prone to bias; especially selection, recall and observer bias, because they rely on memory, and people with a condition will be more motivated to recall risk factors than unaffected controls. For example, for patients admitted to the hospital with a new VTE after ORIF, the disease history as documented in the medical record would have more focus on previous episodes of VTE, family history of thrombophilia, and oral contraception, than for those admitted for an ankle fracture. This increased awareness may lead to differential recall between cases and controls that might increase the association of these variables with VTE following ankle surgery. Case-control studies are cost-effective compared with cohort studies; however, case-control studies are limited to examining one outcome. Such studies are also unable to estimate incidence rates of diseases unless the study is population-based. Hence, this study focused on the identification on risk factors for VTE and did not determine the incidence of VTE throughout the period. 
This study examined risk factors for symptomatic VTE after ORIF for closed ankle fractures in two rather large Norwegian hospitals. However, one should be careful about extrapolation to other populations or procedures.

Routine screening for all possible risk factors may be difficult and may not be cost-effective. Previous studies have suggested that the use of computerized clinical decision support systems may contribute to a more systematic screening of patients for risk factors and select appropriate patients for chemoprophylaxis to prevent VTE in surgical patients [34], although this remains to be tested in prospective studies.

This study has pointed at risk factors for symptomatic VTE following ORIF for closed ankle fractures, but it was not designed to or to have statistical power to determine the efficacy of chemoprophylaxis. This should be assessed in a randomized controlled study. Because the rate of VTEs after ankle surgery is low, it may be feasible to conduct such a study in a population with a higher risk of events, for example among subjects with age $>50$ years and $\mathrm{BMI}>30 \mathrm{~kg} / \mathrm{m}^{2}$, as indicated by the major risk factors in the present study.

In conclusion, this study has determined that increasing age and BMI were associated with higher odds of symptomatic VTE, and increased comorbidity was associated with lower odds of symptomatic VTE within 6 months of ORIF for closed ankle fractures.

Funding: None

Conflicts of interest statement: None Acknowledgements: None 


\section{REFERENCES}

[1] Calder JD, Freeman R, Domeij-Arverud E, van Dijk CN, Ackermann PW. Meta-analysis and suggested guidelines for prevention of venous thromboembolism (VTE) in foot and ankle surgery. Knee Surg Sports Traumatol Arthrosc. 2016;24(4):1409-20.

[2] Ahmad J, Lynch MK, Maltenfort M. Incidence and Risk Factors of Venous Thromboembolism After Orthopaedic Foot and Ankle Surgery. Foot Ankle Spec. 2017;10(5):449-54.

[3] Zheng X, Li DY, Wangyang Y, Zhang XC, Guo KJ, Zhao FC, et al. Effect of Chemical Thromboprophylaxis on the Rate of Venous Thromboembolism After Treatment of Foot and Ankle Fractures. Foot Ankle Int. 2016;37(11):1218-24.

[4] Huntley SR, Abyar E, Lehtonen EJ, Patel HA, Naranje S, Shah A. Incidence of and Risk Factors for Venous Thromboembolism After Foot and Ankle Surgery. Foot Ankle Spec. 2018:1938640018769740.

[5] Solis G, Saxby T. Incidence of DVT following surgery of the foot and ankle. Foot Ankle Int. 2002;23(5):411-4.

[6] SooHoo NF, Eagan M, Krenek L, Zingmond DS. Incidence and factors predicting pulmonary embolism and deep venous thrombosis following surgical treatment of ankle fractures. Foot Ankle Surg. 2011;17(4):259-62.

[7] Pelet S, Roger ME, Belzile EL, Bouchard M. The incidence of thromboembolic events in surgically treated ankle fracture. J Bone Joint Surg Am. 2012;94(6):502-6.

[8] Falck-Ytter Y, Francis CW, Johanson NA, Curley C, Dahl OE, Schulman S, et al. Prevention of VTE in orthopedic surgery patients: Antithrombotic Therapy and Prevention of Thrombosis, 9th ed: American College of Chest Physicians EvidenceBased Clinical Practice Guidelines. Chest. 2012;141(2 Suppl):e278S-e325S.

[9] Hamilton PD, Hariharan K, Robinson AH. Thromboprophylaxis in elective foot and ankle patients--current practice in the United Kingdom. Foot Ankle Surg. 2011;17(2):89-93.

[10] Venous thromboembolism in over 16s: reducing the risk of hospital-acquired deep vein thrombosis or pulmonary embolism. Methods, evidence and recommendations. National Clinical Guideline Centre (UK); March 2018. Report No.: NG89 (volume 1).

[11] Mangwani J, Sheikh N, Cichero M, Williamson D. What is the evidence for chemical thromboprophylaxis in foot and ankle surgery? Systematic review of the English literature. Foot (Edinb). 2015;25(3):173-8.

[12] Jameson SS, Rankin KS, Desira NL, James P, Muller SD, Reed MR, et al. Pulmonary embolism following ankle fractures treated without an operation - an analysis using National Health Service data. Injury. 2014;45(8):1256-61.

[13] Kock HJ, Schmit-Neuerburg KP, Hanke J, Rudofsky G, Hirche H. Thromboprophylaxis with low-molecular-weight heparin in outpatients with plaster-cast immobilisation of the leg. Lancet. 1995;346(8973):459-61.

[14] Kujath P, Spannagel U, Habscheid W. Incidence and prophylaxis of deep venous thrombosis in outpatients with injury of the lower limb. Haemostasis. 1993;23 Suppl 1:20-6.

[15] Riou B, Rothmann C, Lecoules N, Bouvat E, Bosson JL, Ravaud P, et al. Incidence and risk factors for venous thromboembolism in patients with nonsurgical isolated lower limb injuries. Am J Emerg Med. 2007;25(5):502-8.

[16] Shibuya N, Frost CH, Campbell JD, Davis ML, Jupiter DC. Incidence of acute deep vein thrombosis and pulmonary embolism in foot and ankle trauma: analysis of the National Trauma Data Bank. J Foot Ankle Surg. 2012;51(1):63-8.

[17] Felcher AH, Mularski RA, Mosen DM, Kimes TM, DeLoughery TG, Laxson SE. Incidence and risk factors for venous thromboembolic disease in podiatric surgery. Chest. 2009;135(4):917-22. 
[18] Simon MA, Mass DP, Zarins CK, Bidani N, Gudas CJ, Metz CE. The effect of a thigh tourniquet on the incidence of deep venous thrombosis after operations on the fore part of the foot. J Bone Joint Surg Am. 1982;64(2):188-91.

[19] Chao J. Deep Vein Thrombosis in Foot and Ankle Surgery. Orthop Clin North Am. 2016;47(2):471-5.

[20] Jameson SS, Augustine A, James P, Serrano-Pedraza I, Oliver K, Townshend D, et al. Venous thromboembolic events following foot and ankle surgery in the English National Health Service. J Bone Joint Surg Br. 2011;93(4):490-7.

[21] Basques BA, Miller CP, Golinvaux NS, Bohl DD, Grauer JN. Risk Factors for Thromboembolic Events After Surgery for Ankle Fractures. Am J Orthop (Belle Mead NJ). 2015;44(7):E220-4.

[22] Naumann MG, Sigurdsen U, Utvag SE, Stavem K. Associations of timing of surgery with postoperative length of stay, complications, and functional outcomes 3-6 years after operative fixation of closed ankle fractures. Injury. 2017;48(7):1662-9.

[23] Stavem K, Naumann MG, Sigurdsen U, Utvag SE. The association of body mass index with complications and functional outcomes after surgery for closed ankle fractures. Bone Joint J. 2017;99-b(10):1389-98.

[24] International Statistical Classification of Diseases and Related Health Problems 10th Revision: World Health Organization; 2010. http://apps.who.int/classifications/icd10/browse/2010/en.

[25] (NOMESCO) NM-SC. NOMESCO Classification of Surgical Procedures (NCSP), version 1.16 [No authors listed.]. Nordic Medico-Statistical Committee (NOMESCO); 2011 http://www.nordclass.se/NCSP 1 16.pdf.

[26] Rockwood CA, Green DP, Bucholz RW. Rockwood \& Green's fractures in adults. 2010.

[27] American Society of Anesthesiologists - ASA Physical Status Classification System. 2014. http://www.asahq.org/resources/clinical-information/asa-physical-statusclassification-system.

[28] Charlson ME, Pompei P, Ales KL, MacKenzie CR. A new method of classifying prognostic comorbidity in longitudinal studies: development and validation. J Chronic Dis. 1987;40(5):373-83.

[29] Wacholder S, Silverman DT, McLaughlin JK, Mandel JS. Selection of controls in casecontrol studies. III. Design options. Am J Epidemiol. 1992;135(9):1042-50.

[30] Vittinghoff E, McCulloch CE. Relaxing the rule of ten events per variable in logistic and Cox regression. Am J Epidemiol. 2007;165(6):710-8.

[31] Akaike $\mathrm{H}$. A new look at the statistical model identification. IEEE Transactions on Automatic Control. 1974;19(6):716-23.

[32] Richey JM, Ritterman Weintraub ML, Schuberth JM. Incidence and Risk Factors of Symptomatic Venous Thromboembolism Following Foot and Ankle Surgery. Foot Ankle Int. 2018:1071100718794851.

[33] Hanslow SS, Grujic L, Slater HK, Chen D. Thromboembolic disease after foot and ankle surgery. Foot Ankle Int. 2006;27(9):693-5.

[34] Borab ZM, Lanni MA, Tecce MG, Pannucci CJ, Fischer JP. Use of Computerized Clinical Decision Support Systems to Prevent Venous Thromboembolism in Surgical Patients: A Systematic Review and Meta-analysis. JAMA Surg. 2017;152(7):638-45. 
Table 1. Descriptive statistics, number (\%) unless otherwise specified.

\begin{tabular}{|c|c|c|c|}
\hline & VTE & Controls & $P$ \\
\hline$n$ & 60 & 240 & \\
\hline Age, mean (range) & 57.1 (23.6 to 86.1$)$ & 49.3 (18.1 to 93.1$)$ & .0013 \\
\hline Body mass index, $\mathrm{kg} / \mathrm{m}^{2,}$ mean (range) & $30.5(22.7 \text { to } 43.2)^{*}$ & $27.6(17.4 \text { to } 61.0)^{\dagger}$ & .0008 \\
\hline Current smoker & & & .88 \\
\hline No & $42(79)$ & $159(66)$ & \\
\hline Unknown & $3(5)$ & $12(5)$ & \\
\hline Diabetes & $1(2)$ & $14(6)$ & .32 \\
\hline Previous VTE & $3(5)$ & $4(2)$ & .15 \\
\hline Cancer past 5 years & $2(3)$ & $5(2)$ & .63 \\
\hline Use of oral contraceptives & $1(2)$ & $7(3)$ & 1 \\
\hline Charlson comorbidity index & & & .35 \\
\hline 0 & $45(76)$ & $160(68)$ & \\
\hline 1 & $10(17)$ & $46(19)$ & \\
\hline$>=2$ & $4(7)$ & $30(13)$ & \\
\hline ASA status & & & .34 \\
\hline I Completely healthy fit & $21(45)$ & $86(36)$ & \\
\hline II Mild systemic disease & $21(45)$ & $135(56)$ & \\
\hline Uni-,bi-,tri-malleolar & & & .21 \\
\hline Uni & $25(42)$ & $130(55)$ & \\
\hline $\mathrm{Bi}$ & $17(29)$ & $55(23)$ & \\
\hline Tri & $17(29)$ & $51(22)$ & \\
\hline Surgery within $8 \mathrm{~h}$ of trauma & $17(30)$ & $62(26)$ & .54 \\
\hline Syndesmosis screw & $34(57)$ & $114(48)$ & .20 \\
\hline Duration of operation, min, median ( 25 th to 75 th percentile) & $76(54$ to 94$) \ddagger$ & $74(53$ to 104$) \S$ & .93 \\
\hline $\begin{array}{l}\text { Postoperative length of stay in days, median (25th to } 75 \text { th } \\
\text { percentile) }\end{array}$ & 3 (2 to 4$)$ & $3(1 \text { to } 4)^{* *}$ & .31 \\
\hline Thrombosis prophylaxis, yes & $53(88)$ & $224(93)$ & .19 \\
\hline Thrombosis prophylaxis type & & & 1 \\
\hline Dalteparin & $26(49)$ & $108(48)$ & \\
\hline Enoxaparin & $27(51)$ & $114(51)$ & \\
\hline Warfarin & $0(0)$ & $2(1)$ & \\
\hline Thrombosis prophylaxis, days, median (25th to 75 th percentile) & $10(5$ to 13$)$ ף & $11(6$ to 14$)+\dagger$ & .93 \\
\hline Tourniquet during surgery & $44(83)$ & $181(75)$ & .24 \\
\hline Antibiotic prophylaxis & $42(76)$ & $136(57)$ & .007 \\
\hline Treating hospital & & & .91 \\
\hline
\end{tabular}


${ }^{*} n=48,+n=205, \ddagger n=55, \S n=104,9 n=42, * * n=238,++n=213$

VTE, venous thromboembolism; ASA, American Society of Anesthesiologists 
Table 2. Descriptive statistics for patients with VTE according to year of surgery, number (\%) unless otherwise specified.

\begin{tabular}{|c|c|c|c|c|}
\hline & 2004-2008 & 2009-2011 & 2012-2016 & $P$ \\
\hline$n$ & 19 & 15 & 26 & \\
\hline Age, mean (range) & 59.4 (36.8 to 86.1$)$ & 56.7 (34.1 to 75.9 ) & $55.6(28.6$ to 81.8$)$ & .72 \\
\hline Sex, females & $10(52)$ & $7(46)$ & $11(42)$ & .80 \\
\hline Body mass index, $\mathrm{kg} / \mathrm{m}^{2}$, mean (range) & $28.1(23.0 \text { to } 31.5)^{*}$ & $30.6(24.2 \text { to } 41.8)^{\dagger}$ & $31.5(22.7$ to 43.2$) \ddagger$ & .29 \\
\hline Current smoker & & & & .61 \\
\hline Yes & $5(26)$ & $2(13)$ & $8(30)$ & \\
\hline No & $13(68)$ & $13(87)$ & $16(62)$ & \\
\hline Unknown & $1(5)$ & $0(0)$ & $2(8)$ & \\
\hline Diabetes & $0(0)$ & $1(7)$ & $0(0)$ & .25 \\
\hline Previous VTE & $1(5)$ & $0(0)$ & $2(8)$ & .78 \\
\hline Cancer past 5 years & $0(0)$ & $0(0)$ & $2(8)$ & .50 \\
\hline Family history of thrombophilia & $1(5)$ & $1(7)$ & $1(4)$ & 1 \\
\hline Hormone replacement therapy & $0(0)$ & $0(0)$ & $0(0)$ & - \\
\hline Use of corticosteroids & $2(11)$ & $1(7)$ & $1(4)$ & .81 \\
\hline Use of oral contraceptives & $0(0)$ & $0(0)$ & $1(4)$ & 1 \\
\hline Charlson comorbidity index & & & & .97 \\
\hline 0 & $15(79)$ & $10(71)$ & $20(77)$ & \\
\hline 1 & $3(16)$ & $3(21)$ & $4(15)$ & \\
\hline$>=2$ & $1(5)$ & $1(7)$ & $2(8)$ & \\
\hline ASA status & & & & .47 \\
\hline I Completely healthy fit & $4(33)$ & $7(50)$ & $10(48)$ & \\
\hline II Mild systemic disease & $8(67)$ & $5(36)$ & $8(38)$ & \\
\hline III Severe systemic disease & $0(0)$ & $2(14)$ & $3(14)$ & \\
\hline Weber class & & & & .28 \\
\hline$A$ & $0(0)$ & $1(7)$ & $1(4)$ & \\
\hline B & $13(68)$ & $6(40)$ & $15(57)$ & \\
\hline $\mathrm{C}$ & $4(21)$ & $8(53)$ & $9(35)$ & \\
\hline
\end{tabular}


Undetermined/not classifiable

Uni-, bi-,tri-malleolar

Uni

$\mathrm{Bi}$

$\operatorname{Tri}$

Surgery within $8 \mathrm{~h}$ of trauma

Syndesmosis screw

Duration of operation in min, median (25th to 75th percentile)

Postoperative length of stay in days, median (25th to 75 th percentile)

Thrombosis prophylaxis, yes

Thrombosis prophylaxis type

Dalteparin

Enoxaparin

Thrombosis prophylaxis, days, median (25th to 75th percentile)

Tourniquet during surgery

Antibiotic prophylaxis

Treating hospital

Akershus

$\varnothing$ stfold

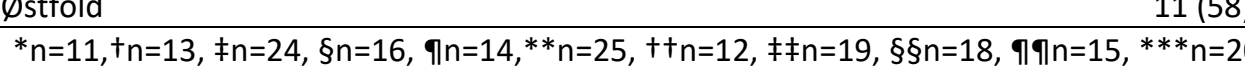

VTE, venous thromboembolism; ASA, American Society of Anesthesiologists
$2(11)$

$0(0)$

$(4)$

$5(26)$

$9(47)$

$5(26)$

$8(44)$

$10(53)$

75 (58 to 113$) \S$

4 (3 to 4)

15 (79)

7 (47)

$8(53)$

6 (4 to 9.5) ${ }^{\dagger \dagger}$

$16(89) \S \S$

$9(60)$

8 (53)

3 (20)

4 (27)

3 (21)

9 (60)

67 (35 to 101)

3 (2 to 5)

14 (93)

6 (43)

8 (57)

11 (9 to 14 )*

11 (73) ๆ१

9 (69)

12 (48)

$5(20)$

8 (32)

6 (24)

15 (58)

81 (64 to 92 )**

2.5 (1 to3)

24 (92)

$13(54)$

11 (46)

10 (6 to 14$) \neq \ddagger$

$17(85)^{* * *}$

24 (96) 


\section{Table 3}

Risk factors for venous thromboembolism (VTE) within 6 months of ORIF for closed ankle fracture, multivariable logistic regression analysis.

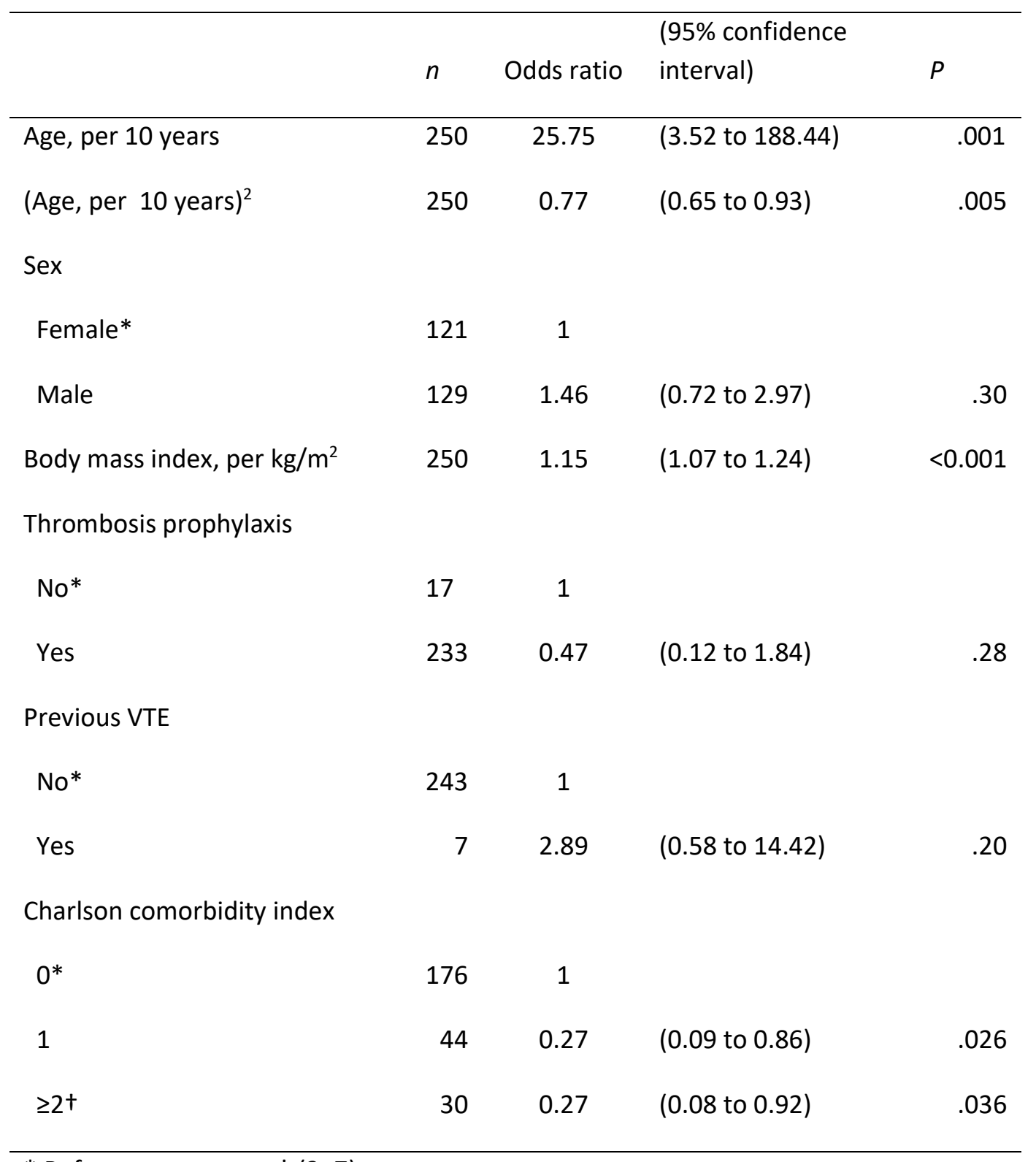

${ }^{*}$ Reference category, ${ }^{\dagger}(2-7)$ 


\section{Figure legend}

Fig.1. Flow chart showing the process of selection of cases with venous thromboembolism (VTE) and controls. 


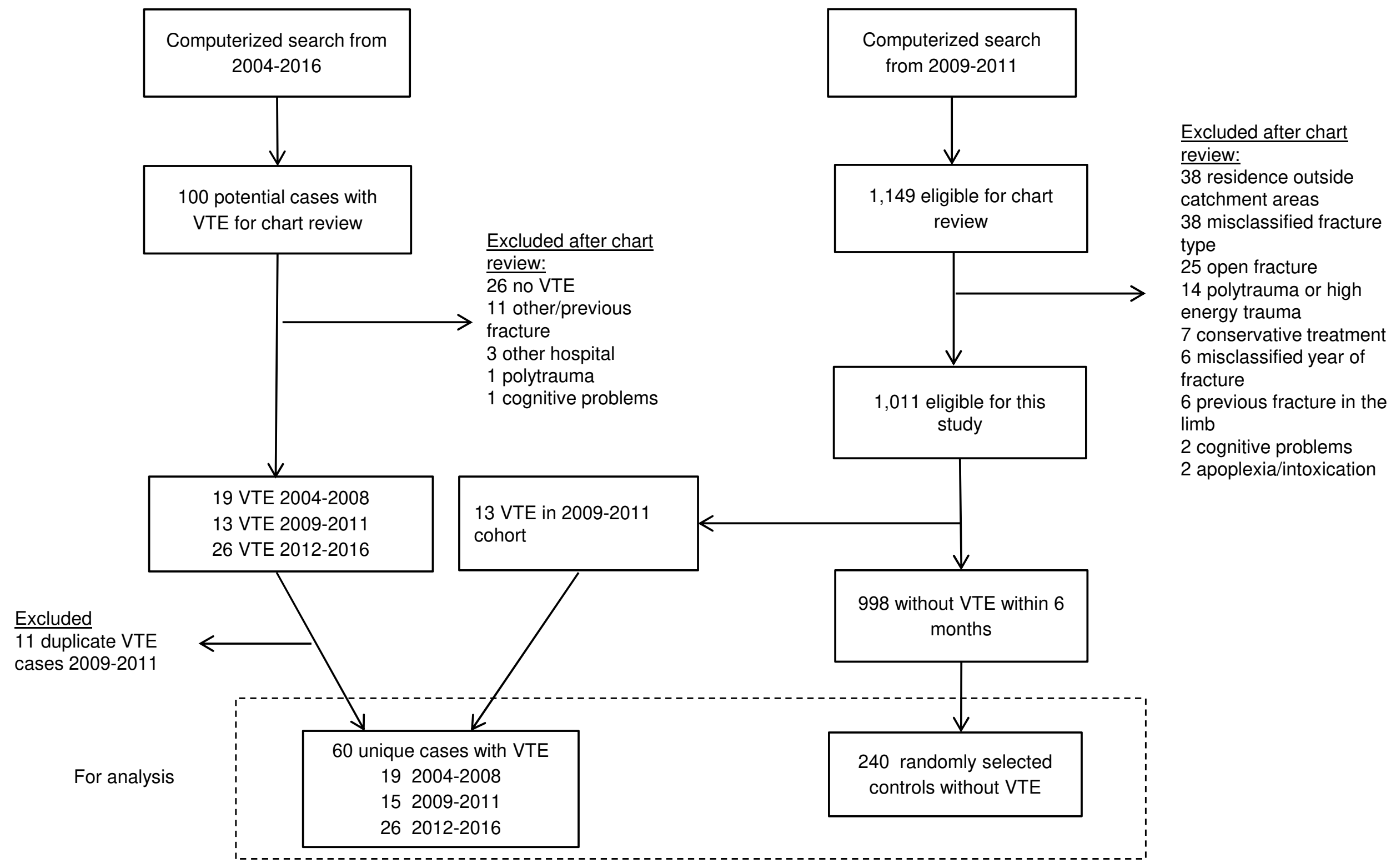

